\title{
A CONSTITUCIONALIZAÇÃO DO DIREITO ADMINISTRATIVO BRASILEIRO SOB UMA VISÃO NEOCONSTITUCIONALISTA
}

\author{
Patrícia Borba Vilar Guimarães ${ }^{151}$ \\ Marcyo Keveny de Lima Freitas ${ }^{152}$
}

Recebido em: $25 / 08 / 2018$

Aprovado em: 25/03/2019

\begin{abstract}
RESUMO
A relação do Direito Administrativo com o Direito Constitucional é de extrema importância para a ciência jurídica haja vista o Direito Constitucional alinhar as bases e parâmetros do Direito Administrativo. Atualmente, há um efeito irradiador dos direitos fundamentais para todas as esferas do Direito e, especificamente, para aquelas relacionadas à atuação estatal. A necessidade de promoção e defesa dos interesses da coletividade, materializada com a garantia dos direitos fundamentais, fez com que o Direito Administrativo, ao longo do tempo, se aproximasse cada vez mais dos valores constitucionais. O Direito Administrativo adquiriu um novo conceito, voltado para a incorporação das normas e valores constitucionais, sendo a Constituição o centro da razão do Estado. A atividade administrativa passou a ser vinculada aos valores constitucionais e ideologias consagradas na Constituição que refletem o posicionamento do Estado perante os valores da humanidade. A Constitucionalização do Direito Administrativo traduz-se em um movimento de releitura de institutos e conceitos básicos da Administração Pública à luz dos princípios constitucionais e não apenas a mera incorporação do direito ordinário ao texto constitucional.
\end{abstract}

Palavras-Chave: Administração pública. Direitos fundamentais. Princípios constitucionais. Direito administrativo. Constitucionalização.

\section{INTRODUÇÃ̃O}

1.1 Breve Relato da Evolução Histórica do Direito Administrativo

\footnotetext{
${ }^{151}$ Doutora em Recursos Naturais pela Universidade Federal de Campina Grande - UFCG. Mestre em Direito pela Universidade Federal do Rio Grande do Norte - UFRN. Mestre pelo Programa Interdisciplinar em Ciências da Sociedade, na área de Políticas Sociais, Conflito e Regulação Social, pela Universidade Estadual da Paraíba UEPB. Professora titular da UFRN. Advogada.

${ }^{152}$ Especialista em Direito Constitucional pela Universidade Federal do Rio Grande do Norte. Advogado.
} 
Os indivíduos no período medieval se relacionavam com o poder de forma especial, como servos, tendo em vista que prevalecia a relação feudal, na qual os senhores feudais eram o centro de todas as decisões, até porque cada feudo possuía sua própria Lei, o Poder era, portanto, descentralizado.

No Período Feudal, em que de um lado estava a Igreja Católica e do outro o Estado, não existia uma diferenciação entre Direito e Moral, e não rara às vezes, tais direitos eram entendidos como simples disposição do governante divino, ou melhor, pelo Estado-Igreja, na medida em que este dispunha sobre as punições aos hereges, impondo penas severas e determinando a morte das pessoas pelo simples fato de não concordarem com aquela crença ou por possuírem convicções filosóficas ou religiosas que iam de encontro aos dogmas impostos pela Igreja.

José dos Santos Carvalho Filho (2006, p. 05) sintetiza que:

O Direito Administrativo, contudo, como sistema jurídico de normas e princípios, somente veio a lume com a instituição do Estado de Direito, ou seja, quando o Poder criador do direito passou também a respeitá-lo. O fenômeno nasce com os movimentos constitucionalistas, cujo início se deu no final do século XVIII. [...] Por isso, pode considera-se que foi a partir do século XIX que o mundo jurídico abriu os olhos para esse novo ramo jurídico, o Direito Administrativo.

Aduz ainda, o renomado Autor que:

No período anterior o regime vigorante era o das monarquias absolutistas, em que
todos os poderes do Estado desaguavam nas mãos do monarca, tornando frágeis as
relações entre o Estado e os súditos. [...] Com a teoria da separação de poderes
concebida por MONTESQUIEU, o Estado, distribuindo seu próprio poder político,
permitiu que em sua figura se reunisse, ao mesmo tempo, o sujeito ativo e passivo
do controle público.

Neste sentido, quanto a evolução do Direito Administrativo frente as noções de diretos e garantias aos cidadãos, houve uma profunda evolução no significado e no valor da Constituição, que acompanhou a mudança do modelo de Estado.

A atuação Estatal progrediu e houve significativas mudanças ao longo do tempo, haja vista não existir propriamente direitos fundamentais na Antiguidade, nem na Idade Média, nem durante o Absolutismo, pois a noção de Estado de direito ainda não estava consolidada. Até porque, não era possível, naqueles períodos, exigir do governante o cumprimento das normas que ele mesmo editava. Somente há sentido em falar em direitos fundamentais quando se admite a possibilidade de limitação jurídica do poder político.

No que tange a evolução histórica do Direito Administrativo e sua mudança de paradigma, Marçal Justen filho (2009, p. 10) elucida que: 
Antes da afirmação do Estado de Direito, a atividade administrativa do Estado era pouco permeável ao direito e ao controle jurisdicional. Os atos do governante não comportavam controle, sob o postulado de que o rei não podia errar ou que o conteúdo do direito se identificava coma vontade do príncipe. A consagração do Estado de Direito refletiu a tendência a eliminar os critérios religiosos e carismáticos como fundamento da legitimação do poder político, já que em um Estado de direito prevalece as leis, e não a vontade do governante.

Com o advento da Revolução Francesa (1789-1799), os poderes constituídos foram criados e separados para que fossem independes e harmônicos entre si, humanizando a sociedade.

A separação dos poderes foi de vital importância, constituindo-se como um marco para a construção da Democracia, pois antes a Lei emanava do Rei "Todo Poderoso", e agora com a criação do Poder Legislativo, os súditos ficariam vinculados a Lei, bem como o Poder Judiciário retiraria do Monarca o poder de julgar.

Assim, o governante, representante do povo e senhor das razões, passou a ser chefe do então novo Poder Executivo, limitado pela Lei, criada por um poder Legislativo novo, livre e autônomo.

Essa separação dos poderes trouxe um equilíbrio para o sistema de poder, suficiente para pôr fim ao Estado Absolutista, déspota, no qual o poder centralizado no monarca desrespeitava constantemente o direito do próximo.

É nos dizeres de Mauro Roberto Gomes de Mattos (2010, p. 25) que:

\begin{abstract}
Esse recuo da Administração autoritária, resultado da evolução dos tempos, colocou de lado a agressividade para dar lugar à fase constitutiva de direitos, onde a mesma é chamada a desempenhar uma atividade prestadora favorável aos particulares, se adaptando ao atual sistema ao Estado Democrático de Direito. [...] Assim, o ato administrativo deixou de ser visto apenas como uma agressão da esfera individual, para passar a ser igualmente um instrumento de satisfação de interesses individuais.
\end{abstract}

Neste diapasão, com o fim do Estado despótico, surgiram os princípios da legalidade, da soberania do povo e da separação dos poderes como fundamento de outras formas de Estado democrático, vinculados ao significado, comando e à determinação da Lei.

Houve nesse período, após uma mudança de paradigmas, o surgimento de uma nova visão acerca do direto de liberdade dos indivíduos, no qual prevalecia o direito de fazer tudo aquilo que as leis permitissem. Essa liberdade normativa passou a ser a base de manutenção dos atos políticos, que passaram a ser vinculados a Lei.

Neste sentido, pode-se afirmar que a Constituição é um parâmetro superior a ser seguido, que autoriza a atuação do Estado frente aos particulares e ao mesmo tempo, limita 
essa atuação sob o prisma dos direitos fundamentais e das garantias constitucionais do cidadão.

Nas palavras de Mauro Roberto Gomes de Mattos (2010, p. 25):

Os princípios, as garantias, e as normas da Constituição é que dão executividade à Lei e, consequentemente, a todo ato público, que deve guardar correção direta com os mandamentos constitucionais, sob pena de sua invalidação.

Indiscutivelmente, a vinculação da Administração Pública à Lei foi uma peça fundamental para o Direito Público e para toda a humanidade, que passaram a se submeter às regras legais e não mais à tirania do Rei.

Ademais, a atuação do governante baseado por esses princípios fez nascer uma nova ideologia quanto a atuação do Poder Público, com a instituição de limites, quer dizer, o poder sendo limitado pelo próprio poder, para evitar abusos e excessos.

Devido a essa consolidação do Estado Democrático de Direito, as Constituições atuais possuem uma elaboração voltada aos direitos e garantias fundamentais do cidadão, invertendo-se a supremacia, em decorrência de que o Estado passou a ser controlado, para justamente proporcionar a todos o bem-estar.

O Estado, portanto, deixou de ser um ente violador dos direitos fundamentais, passando a ser um ente garantidor das prerrogativas constitucionais de cada cidadão, respeitado assim, direitos e garantias e assumindo obrigações frente aos particulares.

A relação do Direito Administrativo com o Direito Constitucional é de extrema importância para a ciência jurídica haja vista o Direito Constitucional alinhar as bases e parâmetros do Direito Administrativo, sendo este, aliás, o lado dinâmico daquele. Assim, é na Constituição que se encontram disciplinados os Princípios da Administração Pública, as normas sobre servidores públicos e as competências do Poder Executivo.

Há, ainda, na Carta Magna de 1988 o instituto do tombamento, da desapropriação, das concessões e permissões de serviços públicos, dos contratos administrativos e licitações, e por fim, da responsabilidade extracontratual do Estado, dentre outros.

Neste sentido, na visão de Mauro Roberto Gomes de Mattos (2010, p. 31):

O Estado, em um primeiro momento, teve que concentrar o Poder (Estado Ditatorial), para em um segundo momento, já fortalecido, procurar o homem, para estabelecer uma organização política e social, preconizada por uma construção de ideias garantidoras da liberdade e dos direitos individuais do cidadão através do expediente da Separação dos Poderes, correspondente a um período liberal.

A atuação do governante deve estar em consonância com a Constituição Federal, no sentido de respeitar e proteger os Direitos alheios. Essa profunda mudança no valor e 
significado da Constituição está diretamente relacionada a radical mudança do modelo de Estado.

Atualmente, há um efeito irradiador dos direitos fundamentais para todas as esferas do direito e, especificamente, para aquelas relacionadas à atuação estatal. $\mathrm{O}$ Direito Administrativo adquire um novo conceito, voltado para a incorporação das normas e valores constitucionais, sendo a Constituição o centro da razão do Estado.

A atual Constituição Cidadã abriu novos caminhos para a contenção de abusos do Poder Administrativo, acenando como um aperfeiçoamento das instituições democráticas, a valorização do homem comum e a maior proteção dos interesses coletivos.

Portanto, com o surgimento e reconhecimento de direitos dos indivíduos, e a valorização dos princípios, o governante não pode mais desrespeitar os governados pelo simples fato de estar no poder, devendo garantir e tutelar interesses coletivos e individuais dos cidadãos, pois sucede, que na atualidade, o Direito Público é voltado para a constitucionalização de suas normas, vinculadas à determinação suprema da Lei Fundamental.

\section{VISÃO PRINCIPIOLÓGICA DO DIREITO ADMINISTRATIVO BRASILEIRO}

Com a queda da onipotência do Estado em face da Constituição, e a consolidação do Estado Democrático de Direito, as Constituições atuais possuem uma alta carga valorativa e se voltam aos direitos e garantias fundamentais do cidadão, invertendo-se a supremacia, em decorrência de que o Estado passou a ser controlado, para justamente proporcionar a todos o bem estar social.

A observância na aplicação e interpretação constitucional das normas e leis que regem a organização do Estado pelo gestor público é de extrema importância, pois a Constituição Federal no seu artigo $5^{\circ}$, inciso XXXV determina que sempre que solicitado, a intervenção do Poder Judiciário, para afastar lesão ou ameaça a direito.

Ademais, nos dizeres de Mauro Roberto Gomes de Mattos (2010, p. 39):

Como todos os Poderes públicos estão obrigados a respeitar as garantias, direitos, princípios e normas constitucionais, qualquer lesão ou ameaça autoriza ao prejudicado a possibilidade de ingresso ao Poder Judiciário, que instando a se manifestar, possui a obrigação constitucional de manter a unidade da Constituição, combatendo, desta forma, violações ao texto constitucional.

O Estado passou por uma fase de transformação ao longo do tempo, deixando de lado sua postura agressiva para consolidar-se em uma administração prestadora e constitutiva. 
Isto porque, os princípios, as garantias e as normas da Constituição é que sustentam o sistema e dão executividade à Lei, e consequentemente, a todo ato público, que deve guardar correlação direta com os mandamentos constitucionais, sob pena de sua invalidação.

A interpretação da Lei com o auxílio dos princípios facilita a organização administrativa, assim como a aplicação da Lei, até porque com o fim da ideia da perfeição da Lei, passou a legalidade administrativa a se vincular a um sistema aberto de regras e de princípios constitucionais, pois a efetividade da Constituição conquistou o status pleno de normas jurídicas, através das quais se leem e interpretam todos os atos públicos, projetado por todo sistema jurídico.

Mauro Roberto Gomes de Mattos (2010, p. 46) expõe que "a vinculação do Estado à legalidade constitucional retira do administrador público a condição de estabelecer uma escolha livre para a tomada do seu ato administrativo afastada dos princípios constitucionais". A sua liberdade não é total na atual fase do direito Administrativo constitucional, sendo, aliás, vinculada aos instrumentos, princípios, garantias, direitos e demais preceitos contidos na Constituição Federal.

A livre escolha administrativa continua a existir, apenas a mesma é vinculada aos princípios da administração pública, para que o cidadão tenha a garantia de que os homens públicos atuarão direcionados aos interesses de todos e não ocorram desvios de finalidade indesejados.

Os princípios constitucionais estão no centro do ordenamento jurídico, e de forma nenhuma poderão ser suprimidos, sob pena de formarmos um grande conjunto de regras vazias, sem finalidade, sem essência definida. A atividade administrativa está vinculada, assim, aos valores supremos constitucionais e ideologias consagradas na Constituição que refletem o posicionamento do Estado perante os valores da humanidade.

Nas palavras de Marçal Justen Filho (2009, p. 03):

O Direito Administrativo se vincula a realização dos direitos fundamentais, definidos a partir da dignidade da pessoa humana [...] disciplinando um setor de atividades e um conjunto de organizações estatais e não estatais para produzir a limitação dos poderes que são gerados por sua existência. O Direito Administrativo visa a evitar que a concentração de poderes políticos e econômicos, relacionados com as atividades de satisfação de interesses coletivos, produza o sacrifício da liberdade e de outros valores fundamentais.

Desta maneira, em um Estado Democrático de Direito, as atividades dos gestores públicos são vinculados sempre aos princípios e preceitos contidos na Constituição para melhor servir ao interesse coletivo. 
A Constitucionalização do Direito Administrativo ganhou força após a segunda Guerra Mundial, em um cenário em que a preponderância e instituição das garantias e direitos fundamentais do ser humano passaram a ser a grande preocupação mundial, surgindo novos valores éticos e morais. Assim, os direitos fundamentais do homem incorporados ao neoconstitucionalismo moderno passaram a ser o traço marcante do Estado, do bem-estar social.

Com a Constitucionalização do Direito Administrativo, os princípios fundamentais desse ramo do Direito deixaram de ser exteriorizados pela legislação infraconstitucional para se posicionar na própria Teoria Constitucional, representada por suas normas, direitos, garantias e seus princípios.

Os princípios previstos na Carta Cidadã de 1988 foram ponderados pelo constituinte para, exatamente, balizar a atuação da Administração Pública, haja vista o direito administrativo, na atualidade, ser um instrumento limitador do poder estatal e não estatal.

Acerca desse fenômeno, preleciona Mauro Roberto Gomes de Mattos (2010, p. 42) que "o novo constitucionalismo se afastou do modelo positivista da jurisprudência dos conceitos e dos valores, para buscar nos princípios fundamentais o seu verdadeiro alicerce de validade". Logo, os princípios constitucionais possuem grande valor normativo, constituindose a própria realidade jurídica, com reflexo em todos os ramos do Direito.

O gestor público deve se ater a aplicação dos princípios na atuação administrativa e nos atos públicos, tendo em vista que pela nova interpretação constitucional são estabelecidas as necessidades de serem cumpridas efetivamente não só as normas, mas, sobretudo, os princípios fundamentais.

Neste tocante, os princípios elencados no art. 37, caput, da Constituição Federal geram para a Administração Pública a obrigatoriedade de observá-los e cumpri-los, sob pena de cometimento de ato ilegal.

Acerca da constitucionalização do Direito Administrativo e sua relação com os princípios constitucionais, aduz Marçal Justen Filho (2009, p. 03) que:

O direito administrativo tem um compromisso com a realização dos interesses coletivos e com a produção ativa dos valores humanos. Há valores fundamentais a serem realizados, cuja afirmação é inquestionável e cuja produção não pode ser deixada às escolhas individuais e egoísticas. [...] $\mathrm{O}$ direito administrativo é o instrumento jurídico e social para a atuação dessas organizações e para a realização dessas atividades. 
Ademais, a constitucionalização das regras da Administração Pública permite ao Poder Judiciário um controle mais efetivo sobre os atos administrativos caso estes venham a colidir com os princípios da legalidade, impessoalidade, moralidade, publicidade e eficiência.

Ressalta-se que na estrutura moderna de Estado não é mais permitido ou aceitável um Estado autoritário, centralizador, com estruturas burocráticas para satisfazer interesses exclusivos de classes dominantes. O Estado assumiu um status social, democrático, dialogando com a sociedade.

Neste diapasão, o Estado não é um fim em si mesmo, mas, sobretudo, um meio de garantia e participação das camadas mais variadas da sociedade, logo, este apenas se justifica como reflexo da sociedade quando atende aos anseios da população, como um instrumento de realização e materialização dos direitos fundamentais, protegendo a dignidade da pessoa humana, defendendo a aplicação e ampliação de políticas públicas/sociais destinadas ao bem estar da coletividade e implementando projetos legislativos.

Portanto, os princípios constituem-se em diretrizes a guiar toda a prática e execução do ato público, resultando em normas gerais e fundamentais para a boa gestão da coisa pública. Ademais, tanto os princípios como as regras de uma Constituição se transformam em normas, porque determinam para toda a sociedade o que deve ser seguido e respeitado.

Assim, os princípios constitucionais funcionam como bases fundamentais do Direito Administrativo. Desta maneira, a vinculação desses princípios ao Direito Administrativo resultou em um maior controle na Administração Pública, pois essa vinculação evita que fins diversos ao interesse público sejam os prevalentes.

\section{A CONSTITUCIONALIZAÇÃO DO DIREITO ADMINISTRATIVO BRASILEIRO SOB UMA VISÃO NEOCONSTITUCIONALISTA}

A Constituição da República Federativa Brasileira está no ápice do ordenamento jurídico nacional, representando, desta maneira, uma mudança de paradigma no Direito Administrativo Brasileiro.

No que tange ao surgimento e evolução do neoconstitucionalismo, Gustavo Binenbojm (2007, p. 103) nos ensina que:

O constitucionalismo moderno surge quando da separação dos regimes absolutistas, advindo da necessidade de contenção do poder do Estado. Tal escopo instrumentalizou-se a partir da proteção de um conjunto de direitos que, positivados 
na Constituição, foram erigidos a um nível hierárquico superior. [...] A grande inovação das Constituições da modernidade consiste em que, permeadas pelos ideais humanistas, posicionam o homem no epicentro do ordenamento jurídico, verdadeiro fim em si mesmo, a partir do qual se irradia um farto elenco de direitos fundamentais. Tais direitos têm assento, sobretudo, nas ideias de dignidade da pessoa humana e de Estado Democrático de Direito, servindo, concomitantemente, à legitimação e à limitação do poder estatal.

No atual estágio do Direito Constitucional, os preceitos fundamentais adquirem relevo significativo, ocupando, desta forma, o centro do patamar dos estudos que têm por objeto a Constituição, assim, a dignidade da pessoa humana é posta como regra basilar, influenciando o conteúdo da atuação da Administração Pública.

No que tange a dicotomia entre o Direito Administrativo e o Direito Constitucional, Marçal Justen Filho assim expõe (2005, p. 1) que:

O direito administrativo é o conjunto de normas jurídicas de direito que disciplinam as atividades administrativas necessárias à realização dos direitos fundamentais e a organização e o funcionamento das estruturas estatais e não estatais encarregadas de seu desempenho.

A Supremacia da Constituição propicia a Administração Pública a obediência aos valores, princípios e normas constitucionais. A observância aos princípios constitucionais elencados na Carta Magna de 1988 é de vital importância para o funcionamento das atividades estatais.

Em um Estado Democrático e Constitucional de Direito, a democracia é verdadeiramente considerada como o governo segundo a vontade do povo quando os cidadãos são tratados como agentes morais autônomos, com igual respeito e consideração. Assim, as condições democráticas são os direitos fundamentais, reconhecidos pela comunidade política através de princípios, sem os quais não há cidadania em sentido pleno.

Os direitos fundamentais desempenham, portanto, papel primordial na relação entre Administração Pública e o cidadão, pois esses direitos são, antes de tudo, uma exigência democrática do que uma limitação à democracia.

A despeito disso, a Carta Fundamental de 1988 trouxe um significativo avanço ao elencar expressamente princípios que regem a Administração Pública Brasileira. Assim, houve uma mudança no modo de agir do agente público, não sendo mais admitidas omissões e condutas arbitrárias do Estado. Há limites e barreiras a serem respeitados quando da atuação do Administrador Público, respeitando sempre a Lei Suprema em suas regras e princípios.

Os direitos fundamentais ocupam um patamar de destaque no ordenamento jurídico pátrio em razão de sua importância democrático-constitucional. A administração pública deve observar os valores constitucionais no trato com os cidadãos, como condição mesma à vida 
em sociedade e a própria proteção e promoção dos aludidos direitos. Logo, o Estado também tutela interesses de cunho particular, e, sobretudo coletivo, voltados a atender demandas que ultrapassam a esfera individual dos governados.

O reconhecimento de direitos de natureza transindividuais autoriza ao Estado a limitação dos interesses individuais em benefício da tutela da coletividade. Assim, cabe ao Estado, em determinados casos, limitar interesses individuais do cidadão, em prol de anseios difusos, como exemplo, podemos citar a proteção ao meio ambiental ecologicamente equilibrado, o instituto da desapropriação, o tombamento e a função social da propriedade.

A Constitucionalização do Direito Administrativo traduz-se em um movimento de releitura de institutos e conceitos básicos da Administração Pública à luz dos princípios constitucionais e não apenas a mera incorporação do direito ordinário ao texto constitucional.

Nas palavras de Marçal Justen Filho (2005, p. 10), a necessidade de observância dos valores fundamentais contidos na Carta Cidadã de 1988, significa que:

\begin{abstract}
A realização dos direitos fundamentais exige não apenas um Estado de Direito caracterizado pela omissão em face da realidade socioeconômica. A evolução da Civilização impõe que esse Estado de Direito incorpore instrumentos de realização de valores essenciais - o que é indicado pela expressão Estado Social e Democrático de Direito.
\end{abstract}

Os princípios constitucionais aplicáveis a Administração Pública em conjunto com a Lei irão orientar a conduta do agente público, logo, em alguns casos a Lei será fundamento básico do ato administrativo, já em outros casos os princípios administrativos com sua alta carga valorativa, utilizando de juízos de ponderação, razoabilidade, proporcionalidade com a legalidade, poderão validar atuações para além ou mesmo contra dispositivos legais.

Destarte, a normatividade proveniente da princioiologia constitucional resulta em uma nova visão da tradicional discricionariedade administrativa, deixando para traz esse espaço de liberdade decisória para ser compreendida como um campo de ponderações proporcionais e razoáveis entre diferentes bens e interesses jurídicos tutelados pela Constituição.

A atuação do Estado deve estar voltada ao interesso público. Neste passo, a conceituação de interesse público, nas palavras de Gustavo Binenbojm (2007, p.104) representa "[...] um conceito jurídico indeterminado por excelência, pode-se afirmar que a expressão aponta, em sentido lato, para os fundamentos, fins e limites a que se subordinam atos e medidas do poder público".

A Administração Pública deve atender ao interesse público da coletividade. $\mathrm{O}$ ato administrativo não tem legalidade se o administrador agiu no interesse próprio, e não no 
interesse público, ainda que obedecida formalmente a letra da lei. Assim, o administrador tem que atender o interesse público no desempenho dos seus atos.

Os valores assegurados constitucionalmente tidos como paradigma da ordem jurídica representam interesses públicos, capazes por si só de serem diretrizes efetivamente vinculantes para o Estado, na concretização de interesses, metas e diretrizes que beneficiem a sociedade, desenvolvidas e implementadas pela Administração pública.

No desempenho de suas funções no Estado Moderno, o governante tem que dialogar com os diferentes grupos sociais, pois a legitimação desse Estado se relaciona com o modo de comunicação entre governo e sociedade. Neste viés, o direito encontra sua base de fundamentação e legitimação no diálogo com a sociedade, no consenso dos cidadãos.

Para que haja a instrumentalização e materialização da vontade da maioria através do consenso, os direitos fundamentais devem, obrigatoriamente, serem reconhecidos, preservados e promovidos. Neste sentido, Marçal Justen Filho (2005, p. 13) preleciona que:

\begin{abstract}
A legitimidade e a validade dos atos estatais não dependem da participação efetiva e real de cada cidadão. Mas somente haverá a legitimidade e a validade quando a disciplina jurídica não excluir essa participação. A validade dos atos estatais pressupõe um sistema jurídico que propicie a participação do cidadão na formação da vontade do Estado. [...] Os governantes e os governados encontram-se em posição de igualdade, ainda que haja competência dos primeiros de tomarem decisões vinculantes para todos.
\end{abstract}

Os poderes do Estado tem pôr fim a busca pela satisfação dos interesses da coletividade, materializada através da plena satisfação dos direitos fundamentais protegidos e fomentados, pelo direito, pelo Estado e por toda a sociedade.

Sobre o tema, Gustavo Binenbojm (2007, p. 766) dialoga com maestria que "o sistema de direitos fundamentais e o princípio democrático, tal como delineados na Constituição, exercem influência decisiva na definição dos contornos da atividade administrativa. À centralidade desses pilares constitutivos e legitimadores da ordem constitucional, deve corresponder uma igual centralidade na organização e funcionamento da Administração Pública”.

Conforme lições de Celso Antônio Bandeira de Mello (1999, p. 15):

O princípio da supremacia do interesse público sobre o particular é o princípio geral do direito inerente a qualquer sociedade, e também como condição de sua existência, ou seja, um dos principais fios condutores da conduta administrativa, pois a própria existência do Estado somente se legitima, se o interesse a ser por ele perseguido e protegido for o interesse público, o interesse da coletividade, haja vista o Estado desempenhar suas funções em detrimento da coletividade, atendendo aos seus anseios. 
Não obstante, o interesse que deve ser atendido é o chamado interesse público primário, referente ao bem estar social coletivo, da sociedade como um todo, que nem sempre coincide com o interesse secundário, referente a órgão estatais ou governantes do momento.

O princípio da supremacia do interesse público sobre o privado tem suas origens no século XIX, em virtude do direito deixar de ser apenas um instrumento de garantia dos direitos dos indivíduos e passar a objetivar a busca pela justiça social, a pacificação social e o bem da sociedade. Os interesses representados pela Administração Pública, estão previstos no Art. 37 da Constituição Federal Brasileira, e se aplica na atuação do princípio da supremacia do interesse público.

Neste diapasão, o Estado moderno tem o dever de tutelar, garantir e preservar os direitos fundamentais do ser humano, assim como a sociedade civil também deve desempenhar tal papel, diante de um Estado Democrático de Direito Garantista, efetivando assim, a materialização dos direitos fundamentais e os objetivos insculpidos na atual Constituição Cidadã, no que tange a solução dos conflitos e a pacificação social.

Com a evolução e transição do autoritarismo exacerbado do Estado para o estágio democrático, o direito administrativo reflete exatamente essa mudança de conceitos e paradigmas. Com a criação e reconhecimento dos Estados Modernos, o controle da atividade administrativa do Estado se tornou uma constante nos ordenamentos atuais. Há o reconhecimento, portanto, pelo Estado, da centralidade do sistema de direitos fundamentais instituídos pela Constituição com uma estrutura de princípios constitucionais que devem ser observados e respeitados.

O respeito aos direitos e garantias fundamentais dos cidadãos deve ser uma constante nos países democráticos, coadunando com tal entendimento, expõe Marçal Justen Filho (2005, p. 14) que:

\footnotetext{
O Estado Democrático de direito caracteriza-se não apenas pela supremacia da Constituição, pela incidência do princípio da legalidade e pela universalidade da jurisdição, mas pelo respeito aos direitos fundamentais e pela supremacia da soberania popular, como também envolve o compromisso com a realização da dignidade dos indivíduos, inclusive por meio de uma atuação ativa e interventiva.
}

Indiscutivelmente, a liberdade conferida ao agente estatal tem de ser exercida de modo proporcional e razoável, compatível com os valores, princípios e regras fundamentais. A conceituação moderna de Estado de Direito nos leva a conclusão de que nenhum poder político se legitima sem o devido respeito à soberania popular e aos direitos fundamentais. 
Conforme já relatado anteriormente, o Estado Moderno também se preocupa e intervém, quando necessário, nas relações entre particulares. É dizer que, essa intervenção se destina a assegurar a realização dos direitos e garantias fundamentais dos cidadãos.

Luís Roberto Barroso (2005, p.12) sintetiza que:

\begin{abstract}
A ideia de constitucionalização do Direito aqui explorada está associada a um efeito expansivo das normas constitucionais, cujo conteúdo material e axiológico se irradia, com força normativa, por todo o sistema jurídico. Os valores, os fins públicos e os comportamentos contemplados nos princípios e regras da Constituição passam a condicionar a validade e o sentido de todas as normas do direito infraconstitucional. Como intuitivo, a constitucionalização repercute sobre a atuação dos três Poderes, inclusive e notadamente nas suas relações com os particulares. Porém, mais original ainda: repercute, também, nas relações entre particulares.
\end{abstract}

A eficácia horizontal dos direitos fundamentais faz com que o Estado Moderno intervenha nas relações entre particulares para proteger e promover os direitos fundamentais, pois o Direito Administrativo não se atém somente na limitação do poder estatal, mas, sobretudo, também impõe ao Estado o dever de intervenção nas relações privadas quando existir excessos, arbitrariedades e abusos.

A função e o conteúdo da Constituição foram esboçados por princípios e valores democráticos em todas as searas jurídicas brasileiras, logo, o Direito Administrativo, assim como as outras áreas do Direito, também adquiriu relevo constitucional em suas normas.

A necessidade de promoção e defesa dos interesses da coletividade, materializada com a garantia dos direitos fundamentais, fez com que o Direito Administrativo, ao longo do tempo, se aproximasse cada vez mais dos valores constitucionais.

A atuação da Administração Pública deve estar comprometida com os valores, princípios e aspirações sociais expressos no texto constitucional. Assim, era necessário constitucionalizar o Direito Administrativo para que a atividade administrativa refletisse os valores constitucionais, de modo a propiciar a realização efetiva dos direitos fundamentais e sociais que estão no bojo da Carta política.

Neste diapasão, ao refletir a atuação e função do Estado com o espírito da Constituição, o País passa a garantir o desenvolvimento de atividades administrativas efetivas. Assim, nos dizeres de Marçal Justen Filho (2005, p. 15):

É fundamental dotar o País de uma Constituição, mas isso não basta para produzir um Estado Democrático ou a realização dos valores desejados. A transformação concreta da realidade social e sua adequação ao modelo constitucional dependem primordialmente do desenvolvimento de atividades administrativas efetivas. $\mathrm{O}$ enfoque constitucionalizante preconizado consiste em submeter a interpretação jurídica de todas as instituições do direito administrativo a uma compreensão fundada concreta e pragmaticamente nos valores constitucionais. 
Na verdade, com a evolução constitucional, a Constituição deixou de ser vista apenas como Lei básica do Estado, convertendo-se em Lei fundamental do Estado e da sociedade.

Na visão de Gustavo Binenbojm (2007, p. 65) o neoconstitucionalismo “[...] realiza uma verdadeira filtragem constitucional do direito, de modo a reintegrar os seus institutos, buscando-se não só evitar conflitos com a Lei Maior, mas também potencializar os valores e objetivos que esta consagra".

Nessa nova temática, os princípios constitucionais adquiriram relevo significativo nos atos administrativos da Administração Pública, logo, houve a valorização extrema do papel condicionante dos princípios (carga valorativa principiológica).

A interpretação do Direito Administrativo deverá, obrigatoriamente, ser aplicada à luz da Constituição, servindo a mesma como um guia ao intérprete para balizar ou equacionar qualquer questão jurídica. Logo, há uma releitura das normas e regras do Direito Administrativo a partir de uma ótica constitucional.

A supremacia da Constituição deve ser o núcleo concreto e real da atividade administrativa do Estado, assim, a atuação do mesmo deve ser inspirado em princípios e valores democráticos e constitucionais, tendo em vista que a Constituição é o instrumento por meio do qual os sistemas democrático e de direitos fundamentais se institucionalizam no âmbito do Estado.

\section{CONSIDERAÇÕES FINAIS}

Com a promulgação da Constituição Federal de 1988, fruto de uma redemocratização do País influenciada por valores humanitários expressos, houve uma ruptura de um regime antidemocrático para uma nova fase do constitucionalismo brasileiro, baseada na preocupação com a garantia e efetivação dos direitos humanos e sociais elencados no bojo da Carta Magna de 1988.

É mister destacar que as Constituições anteriores a Carta Política de 1988 possuíam regras e valores que não eram observados, ficando a margem dos valores constitucionais estabelecidos, assim, havia uma total inefetividade constitucional.

A Constituição irradiou valores sociais e humanísticos nas mais diversos áreas do Direito. A interpretação conforme a Constituição é uma realidade constante nos órgãos do Estado (decisórios e/ou executivos) de nossa sociedade, como postulado da supremacia 
constitucional e da unidade da ordem jurídica. Neste sentido, o Direito Administrativo adquiriu relevo constitucional, tendo sido influenciado pelo movimento moderno de constitucionalização do Direito.

A Constituição está no ápice do ordenamento jurídico brasileiro, e suas regras possuem presunção de constitucionalidade e legitimidade em respeito ao princípio democrático. Todas as autoridades públicas encontram-se vinculadas negativa e positivamente a Constituição, não lhes sendo permitido a violação de dispositivos constitucionais, cabendolhes também a implementação de comandos e a concretização dos valores constitucionais.

A atuação do Administrador Público encontra limites nos próprios princípios constitucionais, a normatividade decorrente da principiologia constitucional produz uma redefinição dos atos da Administração Pública, logo, o agir administrativo deverá observar e respeitar os ditames da Lei Maior.

A busca pela justiça social e pelo estar social, fez com que o Direito Administrativo se moldasse à luz da Constituição, na garantia das prerrogativas e direitos aos governados. Logo, a Administração Pública deve, necessariamente, observar os ditames constitucionais quando de sua atuação, na tomada de decisões e quando do cumprimento dos atos administrativos.

A constitucionalização do Direito Administrativo, portanto, determina a vinculação direta da Administração à Constituição, adequando a legalidade em juridicidade administrativa, na medida em que a Lei deixa de ser o único fundamento da atuação da Administração pública para se tornar apenas mais um dos princípios do sistema de juridicidade estabelecido pela Constituição.

O Direito Administrativo constitucionalizado reconhece a dimensão objetiva e subjetiva dos diretos fundamentais, quando impõe ao Estado a proteção e promoção desses direitos para com os indivíduos. Assim, os direitos fundamentais carregam em si valores concretizadores, que devem ser protegidos e fomentados pelo Direito, pela sociedade, e sobretudo, pelo Estado.

A atividade administrativa, no atual cenário constitucional brasileiro, é influenciada diretamente pelo sistema de direitos fundamentais e pelo princípio democrático na centralidade da organização e funcionalidade da Administração Pública.

O Estado é, assim, uma realidade instrumental por meio do qual todos os órgãos estatais tem como objetivo a busca pela satisfação plena dos direitos fundamentais e sociais insculpidos na atual Constituição Cidadã, promovendo, desta forma, a dignidade da pessoa humana, para se alcançar a pacificação social, e consequentemente, e o bem estar da coletividade. 
A constitucionalização do Direito Administrativo, portanto, irradia uma nova forma de atuação da Administração Pública à luz da Constituição, pautada no respeito e observância aos princípios constitucionais e aos valores fundamentais emanados da Carta Maior de 1988. Desta forma, o papel do Estado será o de proteger e implementar medidas protetivas e promocionais necessárias a uma otimizada concretização das dimensões subjetiva e objetiva dos direitos fundamentais.

\section{REFERÊNCIAS}

BANDEIRA DE MELlO, Celso Antônio. Curso de Direito Administrativo. 11. ed., São Paulo: Malheiros, 1999.

BARROSO, L. Roberto. Neoconstitucionalismo e Constitucionalização do Direito (O triunfo tardio do direito constitucional no Brasil)". A Constitucionalização do Direito: Fundamentos Teóricos e Aplicações Específicas. Rio de Janeiro: Lúmen Júris, 2007.

BINENBOJM, Gustavo. Uma Teoria de Direito Administrativo: direitos fundamentais, democracia e constitucionalização. $1^{\text {a }}$. Ed. Rio de Janeiro: Renovar, 2006.

DOS SANTOS CARVALHO FILHO, José. Manual de Direito Administrativo. $15^{\mathrm{a}}$ ed. Rio de Janeiro: Lumen Juris, 2006.

JUSTEN FILHO, Marçal. Curso de Direito Administrativo. 4. ed. rev., atual e ampl. São Paulo: Editora Revista dos Tribunais, 2009.

MADAUAR, Odete. Direito Administrativo Moderno. 17. ed., São Paulo: Revista dos Tribunais, 2013.

MATTOS, Mauro Roberto Gomes de. Tratado de Direito Administrativo Disciplinar, $2^{\mathrm{a}}$ Ed., Rio de Janeiro: Ed. Forense. 2010.

SARMENTO, Daniel Antônio de Moraes (Org.); SOUZA NETO, Cláudio Pereira (Org.). A Constitucionalização do Direito: fundamentos teóricos e aplicações específicas. Rio de Janeiro: Lumen Juris, 2007. 
THE CONSTITUTIONALIZATION OF BRAZILIAN ADMINISTRATIVE LAW UNDER A NEOCONSTITUTIONAL VISION

\begin{abstract}
The relationship between Administrative Law and Constitutional Law is of the utmost importance for legal science since Constitutional Law must align the bases and parameters of Administrative Law. Currently, there is an irradiating effect of fundamental rights for all spheres of law, and specifically for those related to state action. The need to promote and defend the interests of the community, materialized with the guarantee of fundamental rights, has made Administrative Law, over time, increasingly approach constitutional values. Administrative Law has acquired a new concept, aimed at incorporating constitutional norms and values, and the Constitution is the center of the State's reason. Administrative activity has become linked to the constitutional values and ideologies enshrined in the Constitution that reflect the position of the State towards the values of humanity. The Constitutionalisation of Administrative Law translates into a movement to reread institutes and basic concepts of Public Administration in light of constitutional principles and not just the mere incorporation of ordinary law in the constitutional text.
\end{abstract}

Keywords: Public administration. Fundamental rights. Constitutional principles. Administrative law. Constitutionalisation. 